\title{
FRANCISCO CERVANTES DE SALAZAR, UN HUMANISTA ENTRE DOS MUNDOS: APUNTES BIBLIOGRÁFICOS
}

\section{FRANCISCO CERVANTES DE SALAZAR, AN HUMANIST BETWEEN TWO WORLDS: BIBLIOGRAPHICS NOTES}

\author{
Víctor Manuel Sanchis Amat ${ }^{1}$. Universidad de Alicante. España. \\ victor.sanchis@ua.es
}

\section{RESUMEN}

El artículo analiza, en primer lugar, la recepción crítica de la única obra conocida de Francisco Cervantes de Salazar publicada en España en el año 1546 en la imprenta alcalaína de Juan de Brócar. Por otro lado, el artículo pretende también destacar el complejo recorrido bibliográfico que la Crónica de la Nueva de la España y el Túmulo Imperial de la ciudad de México (junto con los diálogos de México en 1554 las obras más importantes del humanista en territorio americano) han tenido en los diferentes contextos de recepción en los que se ha insertado la obra del humanista. Aportando en el proceso múltiples miradas a través de las cuales analizar tanto a la obra, como a su autor y su importancia relativa dentro del flujo de literatura novohispana y posterior historiografía, que incluye análisis de interés objetivo para la comprensión del contexto científico de los relatores implicados.

PALABRAS CLAVE: Cervantes de Salazar, bibliografía, Crónica de la Nueva España, México, literatura novohispana, Túmulo Imperial, humanismo.

\section{ABSTRACT}

This article analyzes, first, the critical reception of the only known work by Francisco Cervantes de Salazar published in Spain in 1546 in Alcala printing Juan de Brocar. On the other hand, the article also aims to highlight the complex bibliographic journey of the Crónica de la Nueva España and Tumulo Imperial de la gran Ciudad de México (with dialogues Mexico in 1554 the most important works of the humanist on America). This works have had different contexts of reception in which is inserted the work of the humanist.

KEY WORDS: Cervantes de Salazar, bibliography, Crónica de la Nueva España, Mexico, New Spain literature, Túmulo Imperial, humanism.

\section{Cómo citar el artículo:}

Sanchis Amat, V. M. (2015). Francisco Cervantes de Salazar, un humanista entre dos mundos: apuntes bibliográficos. Revista de Ciencias de la Comunicación e Información, 20, 9-27.

DOI: http://doi.org/10.35742/revistacccomunicacioneinformacion.2015.20.9-27

\footnotetext{
1 Víctor Manuel Sanchis Amat: Universidad de Alicante. Departamento de Filología Española, Lingüística General y Teoría de la Literatura. Alicante, España.
} 


\section{INTRODUCCIÓN}

El toledano Francisco Cervantes de Salazar fue uno de los intelectuales más destacados en el proceso de adaptación del humanismo de corte filológico al continente americano durante el proceso de colonización europea en el siglo XVI. El profesor de retórica, formado en la tradición pedagógica humanista de la España de la corte de Carlos V, heredera de los postulados teóricos de intelectuales afines al erasmismo, tuvo como maestros a personajes de la talla de Alejo de Venegas y relaciones profesionales con figuras como el mismo Juan Luis Vives, al que conoció en Flandes, Juan Maldonado, Hernán Pérez de Oliva, Ambrosio de Morales o el Cosmógrafo Mayor de Indias, su amigo López de Velasco.

Después de unos años al servicio del cardenal de Sevilla, García de Loaisa, como secretario de latines, Cervantes de Salazar completó su formación en la Universidad de Osuna y decidió marchar a la Nueva España hacia 1550 en busca de un beneficio profesional que le haría convertirse en una de las personalidades más destacadas de las letras novohispanas del siglo XVI. (Millares Carlo, 1986).

Además de sus veinte años de servicios a la Real y Pontificia Universidad de México, de la que fue profesor de retórica y rector hasta en dos ocasiones, se convirtió por orden del Cabildo en el primer cronista de la ciudad de México en la década de los 60 , para quién redactó una crónica de la expedición mesoamericana de Hernán Cortés, truncada en 1566, una descripción de los festejos por la jura de la ciudad a Felipe II y la relación de las exequias que la ciudad de México preparó en 1559 tras el fallecimiento de Carlos V.

En estas líneas continuamos la actualización bibliográfica de la recepción de alguno de los escritos más importantes del humanista novohispano que ya comenzamos en un trabajo en la revista Tiempo y Escritura (Sanchis Amat, 2015). El legado intelectual del humanista ha tenido un interés crítico importante, como decíamos, a partir sobre todo de la reedición española de Francisco Cerdà i Rico en 1772 de las Obras que Cervantes ha hecho, glosado y traducido y del trabajo del historiador mexicano Joaquín García Icazbalceta en el siglo XIX para rescatar del olvido los diálogos escolares publicados en México en 1554, traducidos y reeditados en 1875 , y la descripción del Túmulo Imperial de la gran ciudad de México, impresa en 1560 en la imprenta de Antonio de Espinosa.

Aun así, el aprovechamiento de los manuscritos de la Crónica por parte de cronistas de Indias posteriores como López de Velasco o Antonio de Herrera y las referencias en las recopilaciones bibliográficas de Nicolás Antonio o León Pinelo en el siglo XVII muestran la temprana recepción de los textos y la vida del humanista, que ha llegado de manera dispersa desde el siglo XVI hasta las recientes propuestas de paternidades de obras como El lazarillo de Tormes (Madrigal, s.f.) o los gozos a la virgen incluidos en Los sirgueros de la virgen, de Francisco Bramón (2007).

\section{OBJETIVOS}

El artículo analiza, en primer lugar, la recepción crítica de la única obra conocida de Cervantes de Salazar publicada en España en el año 1546 en la imprenta alcalaína 
de Juan de Brócar, donde Cervantes de Salazar traduce y glosa la Introducción para la sabiduría de Juan Luis Vives; edita y glosa una obra sumamente rara en la bibliografía española del Renacimiento, el Apólogo de la ociosidad y el trabajo, compuesto por el protonotario Luis Mexía; y edita, continúa y moraliza una de las páginas más bellas de la prosa española del siglo XVI, el Diálogo sobre la dignidad del hombre, del que fuera rector de la Universidad de Salamanca, el maestro Hernán Pérez de Oliva. Cuál ha sido la fortuna editorial y cuál reinterpretación crítica posterior son las cuestiones en torno a las cuales debate el presente trabajo.

Por otro lado, el artículo pretende también destacar el complejo recorrido bibliográfico que la Crónica de la Nueva de la España y el Túmulo Imperial de la ciudad de México (junto con los diálogos de México en 1554 las obras más importantes del humanista en territorio americano) han tenido en los diferentes contextos de recepción en los que se ha insertado la obra del humanista, a la deriva entre el frecuente olvido de los escritores españoles que publicaron en América en la tradición crítica española y la resemantización del significado de las obras novohispanas que los polígrafos de la independencia realizaron del pasado virreinal en las nuevas repúblicas americanas.

\section{METODOLOGÍA}

El artículo parte de la reflexión necesaria sobre la importancia de las fuentes en la investigación en ciencias sociales y humanidades. Como puede comprobar el lector, el trabajo pretende convertirse en una herramienta bibliográfica para el investigador en literatura, historia, pedagogía e historia del arte del siglo XVI en el virreinato de la Nueva España, ligada a las líneas de investigación que engloban la implantación del humanismo europeo en territorios americanos.

Al tratarse de una revisión bibliográfica, la metodología del estudio se configura precisamente en el establecimiento de un criterio de selección y análisis de los trabajos que desde un punto de vista diacrónico han abordado la figura del humanista toledano Francisco Cervantes de Salazar.

Nos situamos ante un personaje y un movimiento que recorre buena parte del siglo $\mathrm{XVI}$, por lo que el acceso a las fuentes ha sido fundamental para esta actualización bibliográfica. Las obras de Cervantes se encuentran disponibles y de acceso al investigador en la Biblioteca Nacional de Madrid y en las Bibliotecas históricas de la Universidad Complutense, de la Universidad de Valencia y de la Universidad de Valladolid. Ha sido imprescindible también el trabajo en las bibliotecas y archivos mexicanos, gracias al apoyo del Instituto de Estéticas y del Seminario de Cultura Literaria Novohispana, situado en la Biblioteca Nacional de México, en la Universidad Nacional Autónoma de México, que me ha permitido acceder a buena parte de la documentación bibliográfica existente sobre las obras publicadas en México por Cervantes de Salazar.

La gestión de la información se ha hecho a través del gestor bibliográfico RefWorks, donde se han recopilado estudios procedentes de diferentes bases de datos especializadas en el ámbito de la cultura del siglo XVI, como Dialnet o la Biblioteca 
Virtual Miguel de Cervantes en el caso español o Scielo y Redalyc en el ámbito hispanoamericano.

\section{DISCUSIÓN}

\subsection{Actualización bibliográfica y recepción de las Obras que Cervantes de Salazar ha hecho glosado y traducido, Alcalá, Juan de Brocar, 1546}

En 1546 Cervantes de Salazar imprime en uno de los núcleos del erasmismo español, la imprenta alcalaína de Juan de Brocar, hijo del ilustre impresor de la Biblia Políglota, Arnao Guillén de Brocar, una obra miscelánea de tres tomos en un solo volumen en la que el humanista traduce, glosa y edita textos contemporáneos afines al humanismo de corte moralizante de principios del siglo XVI. El título entero de la obra, con su explicación, dice así:

Obras q[ue] Francisco Ceruantes de Salazar, ha hecho,// glosado, y traduzido.// La primera es la introducio[n] y camino pa//ra la sabiduria, do[n]de se declara que cosa sea, // y se ponen grandes auisos para la vida hu-//mana, compuesta en latin por el excele[n]te va-//ron, Luys viues, buelta en Castellano, con II muchas adiciones que al proposito hazian /I por: Francisco Ceruantes de Salazar. // La segunda es el Appologo dela ociosi-//dad y el trabajo, intitulado Labricio Portundo, donde se trata con marauilloso estilo // delos grandes males dela ociosidad, y por || el contrario de los prouechos y bienes del || trabajo, Compuesto por el Protonotario /I Luys Mexia glosado y moralizado por 1Fra[n]cisco Ceruantes de Salazar. // La tercera es vn Dialogo dela dignidad || del hombre, donde por manera de disputa se // trata delas gra[n]dezas y marauillas que ay // en el ho[m]bre, y por el co[n]trario de sus trabajos /| y miserias, come[n]çado por el maestro Oliua, II y acabado por Fra[n]cisco Cerua[n]tes de Salazar. (Cervantes de Salazar, 1546, Portada)

La edición, de la que hoy se conservan varios ejemplares en la Real Biblioteca, en la Biblioteca Histórica de Santa Cruz de Valladolid o en los fondos históricos de la Universidad Complutense y la Universidad de Valencia, se imprimió en un volumen en $4^{\circ}$, de veinte centímetros, encuadernados en pergamino flexible con abrazaderas. La caja de impresión se compone de título, texto y glosas al margen. Se imprimió con un tipo de letra gótica, con capitales y colofones en lámpara. Los tomos del volumen se abren con la misma portada, con el título completo de la obra en tipos rojos y negros enmarcados en una orla. El orden varía dependiendo del ejemplar y no se corresponde con lo que marca el título, ya que probablemente circularan por separado. Los paratextos de la edición presentan una carta nuncupatoria a Hernán Cortés, firmada por Cervantes, donde el humanista da buena cuenta al conquistador del contenido de su libro, un prólogo de Alejo de Venegas, con una breve glosa biográfica y una explicación del trabajo de Cervantes y una carta final del impresor Juan de Brocar.

En el contexto de la ilustración española, el humanista alicantino Francisco Cerdà i Rico reedita en 1772 el volumen de las Obras en la imprenta de Antonio de Sancha con el título de Obras qve francisco cervantes de salazar ha hecho glossado $i$ tradvcido. Dialogo de la dignidad del hombre por el M. Oliva i por Cervantes. 
Apologo de la ociosidad i el trabajo, intitulado Labricio Portundo, por Lvis mexia, glossado por $F$. Cervantes. Introdvcción i camino para la sabiduria compuesta en latin, como va ahora, por Jvan Lvis Vives, vvelta en castellano con mvchas adiciones por el mismo Cervantes. El polígrafo cambia de orden las obas con respecto a la edición original, agrega una extensa nota introductoria en la que analiza el contenido de los textos que edita Cervantes y la tradición en la que se insertan y dispone como prólogo el Discurso sobre la lengua de Ambrosio de Morales, sobrino de Hernán Pérez de Oliva, autor del Diálogo de la dignidad del hombre.

La primera obra que publica Cervantes es la continuación del Diálogo de la dignidad del hombre, al que el humanista añade un extenso final en el que cambia la estructura y la moralización de un texto que no había sido editado hasta el momento. En la edición del Diálogo que prepara Ambrosio de Morales en la imprenta cordobesa de Gabriel Ramos Bejarano en 1586 no aparece la sentencia final moralizadora de Dinarco, juez del diálogo, que Cervantes agrega en 1546 como ejercicio retórico para cerrar un texto que el humanista creía inacabado.

Las primeras impresiones sobre el trabajo de Cervantes son del propio humanista y de su maestro Alejo de Venegas. Cervantes explica las motivaciones de su continuación en la epístola que dirige a Hernán Cortés:

La obra es un Dialogo que se intitula de la dignidad del hombre, en el qual, siendo interlocutores Aurelio, Antonio i Dinarco, se trata por una parte i por otra copiosamente de las miserias, i también las maravillas del hombre. Esto tenia yo determinado en un tiempo tratarlo, i vino a la razón a mis manos el principio deste Dialogo, compuesto por el maestro Hernán Pérez de Oliva, natural de Cordova: de cuyo ilustre ingenio, singular doctrina en todo genero de disciplinas, i extremada gracia en el decir, con que mostró no faltarle mas a nuestro lenguage de buenos juicios que se empleassen en él, no osaré comenzar a decir nada en la estrechura de una carta, principalmente ocupada en otro cuidado: i aunque me hallasse mui libre para estenderme en esto, como conviene, siempre quiero mas que gusten del maestro Oliva, i lo estimen por sus obras lo que las leen, que no por lo que yo puedo apreciarlo, por mucho que con mis palabras lo encarezca. I estoi bien seguro, que quien leyendo el principio de este Dialogo, quisiere advertir, terná por justo este mi miedo de emplearme en alabar su autor, sabiendo lo mucho que descubre, por do merece ser alabado. Yo quando lo leí, después que me admiré del, viendo que respondía a mi deseo i propósito de escrivir lo mismo, tuve por mejor proseguirlo, (pues el maestro Oliva no lo avia acabado) que emprender la obra de nuevo, do mudando el estilo, me pudiera aprovechar de todo lo que él trabajó. Mas como nada ambicioso de gloria, i deseoso de esclarecer la agena, no solamante no quise hacerlo, como pudiera, mas antes acabando la postrera platica de Antonio, que no avia dado fin en contar las maravillas del hombre, en persona de Dinarco, que avia de ser juez, torné a tratar lo mesmo que Aurelio i Antonio digeron, por tal manera, que parece averles faltado de decir lo que yo aquí escrivo. Con esto doi mas luz i esclarezco mas la obra del maestro Oliva: porque dejado que soi parte para que sea en público este su Dialogo admirable, crecerá su valor, y parecerá mas hermoso su principio con la fealdad del fin, con que yo lo concluyo. Aunque es tanto lo que yo he añadido, 
que por sí solo pudiera hacer un libro, i salir a la luz, sin ser afeado de otro mas hermoso (Cervantes de Salazar, 1772) ${ }^{2}$.

El maestro Venegas en su prólogo al «benigno y pío lector» describe el trabajo de Salazar como una continuación y agradece al humanista la virtud de atribuir la obra a Pérez de Oliva, pese a que el sentido final haya sido modificado:

La segunda obra es un diálogo, que trata de las maravillas i de las miserias contrarias que en el hombre se hallan, no digo de la composición de los miembros, en la qual materia Cervantes de escrivió diez i ocho libros Galeno, i después Marcio Geleoto, i ahora en nuestros tiempos Bassiano Lando, sino de las felicidades i adversidades que debajo del hombre se encierran. En el qual argumento escrivió acertadamente el papa Inocencio, i ahora en Romance el maestro Oliva, varón por cierto digno de ser contado en el catalogo de los doctos. Mas como este argumento viniesse a la mano de nuestro Francisco Cervantes, supo estender la pluma i añadió mas de dos tantos a la materia que el maestro Oliva avia comenzado; i pudiendo callar el nombre del guiador, por el zelo que tiene a que la virtud sea premiada, quiso que pareciesse el ingenio del que tan buen argumento emprendió (Alejo de Venegas en Cervantes de Salazar, 1772).

Francisco Cerdá i Rico reimprime, edita y anota el volumen de Cervantes de Salazar, añadiendo una extensa «Advertencia sobre esta nueva impression», en la que ofrece su opinión sobre la adición al Diálogo, alabando la prosa del maestro Oliva y destacando la erudición del joven Cervantes:

Yo, aviendo cotejado entre sí con particular atención los trabajos de ambos escritores de este Diálogo, no dudo dar preferencia al maestro OLIVA en la pureza del estilo, que tan ventajosamente supo conseguir, en lo atinado de su juicio, solidez de sus razonamientos, i orden que guardó en toda la obra; i a CERVANTES en la erudición esparcida por todo su discurso. Aquel la usa con mas moderación, aunque se muestra mui versado en la lectura de los autores antiguos, de quienes copia los mejores pensamientos: este quiso manifestar la mucha que tenia en una edad, en que otros emplean sus años inútilmente; pero lo que mas realza el merito de CERVANTES es, que supo estender la pluma, como pondera con mucha razón VENEGAS, i añadió mas de dos tanto a la materia que el maestro Oliva avia comenzado (Cerdà i Rico, 1772, pp. VII-VIII).

María Luisa Cerrón Puga recoge en su edición en Letras Hispánicas del Diálogo de Pérez de Oliva los testimonios negativos de Menéndez Pelayo y de Antoni Capmany sobre la obra, y los achaca a la continuación de Cervantes:

No obstante, para Menéndez Pelayo el Coloquio de la dignidad del hombre «no es tal coloquio, sino tres disertaciones escolásticas, pronunciadas una tras otra por tres personajes fríos e inanimados que no se distinguen entre sí más que por los nombres». Historia de los heterodoxos españoles (Santander, Aldus,

\footnotetext{
${ }^{2}$ El paginado de las ediciones de las Obras es confuso, ya que son tres obras en una, cada una con su cubierta y su numeración. El lector que se acerque al texto podrá localizar las citas en la edición de 1772 con las indicaciones proporcionadas.
} 
1946: IV, 2). Pero tanto él como Capmany, quien acusa al Diálogo de ser una disputa pesada e insípida entre tres interlocutores (Teatro histórico-crítico de la elocuencia española, Madrid, 1786: II, 17) parecen hablar del Diálogo editado por Cervantes de Salazar, quien añadió al texto su aportación personal; eso es lo que explicaría la dureza de los juicios, pues el añadido es farragoso, sobre todo en contraste con la ligereza de la prosa de Pérez de Oliva (Cerrón Puga, 1995, p. 34).

En esta línea, Francisco Rico califica el trabajo de Cervantes en el capítulo que dedica a la dignidad del hombre en su ensayo El pequeño mundo del hombre como «continuación apresurada». Sin embargo, pese a las traducciones «desmañadas» 0 a la «poquita cosa» como texto literario, Francisco Rico pondera positivamente las consideraciones que Cervantes escribe sobre el alma, de raigambre aristotélica, y la importancia de la toma de contacto con la moderna doctrina communis, aspecto decisivo para la formación del joven humanista toledano:

El párrafo de Cervantes de Salazar [sobre el tópico del De anima aristotélico: fol. LXXVI y vo.], con sus pretensiones filosóficas casi en la tradición de la jerga técnica de la escuelas, contrasta en andadura con el prólogo a La Lengua de Erasmo nuevamente romançada por muy elegante estilo, pero en varios aspectos se le arrima en intención. Es aquel prefacio, diría yo, una de las páginas más bellas, mejor construidas, más sugestivas del Renacimiento español. (Rico, 2005, pp. 113-114)

El único estudio contemporáneo específico sobre el trabajo de Cervantes con el Diálogo de la dignidad del hombre es el de Consolación Baranda, que inserta la obra en el contexto del género del diálogo y analiza el cambio estructural que se produce entre el planteamiento de Pérez de Oliva y la resolución final que añade Cervantes de Salazar en su continuación (Baranda, 2003, pp. 22-24).

La obra más desconocida de las tres que conforman el volumen es sin duda el Apólogo sobre la ociosidad y el trabajo, compuesto por el protonotario Luis Mexía. El silencio de Cervantes y de Alejo de Venegas en la introducción sobre el autor han convertido al protonotario en un intelectual sin más biografía que este Apólogo, género rescatado en el Renacimiento como herramienta pedagógica y moralizadora, en el que se plantea un enredo entre personajes con nombres alegóricos en torno a la necesidad de seguir la senda de la virtud para alcanzar la recompensa de un casamiento provechoso y feliz.

El humanista toledano es el primero en ofrecernos una crítica de la obra en los paratextos que acompañan al Apólogo. En la dedicatoria al «llustre y reverendísimo señor don Juan Martínez Silício», Cervantes destaca la lección moral de este tipo de ficciones, tan del gusto de la corriente didáctica en la que se estaba formando el joven humanista y plantea la necesidad de aclarar a través de glosas los pasajes eruditos:

Vino a mis manos este Apólogo, obra por cierto digna que no se dirigiesse a otro, que V. S. pues con tan gran artificio, eloquencia i erudición se trata en él de los grandes daños que la ociosidad acarrea; i por el contrario, de los 
muchos vienes que el trabajo trae consigo. Va tan bien ordenado, que tiene lo que Horacio pide que aya, que deleitando juntamente enseña: porque debajo de mui gustosa ficion enseña maravillosamente, como se ha de trabajar en la vida, i como, pues nacimos para no estarnos mano sobre mano, sino para entender en grandes cosas, quales son para las que Dios nos crió, que es para gozar de su reino, avemos siempre de emplearnos en ellas. Imitó en esto bien el autor a los grandes poetas, a los quales si quitaren las mascaras de las ficiones, hallarán debajo grandes secretos de philosophia; porque fingiendo que Daphne se convirtió en laurel, dieron a entender la virginidad, que, como el laurel, siempre está fresca. I ansí fingiendo también, que Acteón vuelto en ciervo le despedazaron sus perros, quisieron decir la pobreza, a que vienen los cazadores, por comerles los perros la hacienda. Assi casi por la mesma manera finge el autor, que uvo una señora regalada señora llamada Ocia, que es la ociosidad, i un cavallero natural de España por nombre Labricio, entre los quales se trató un casamiento, como mas largamente parecerá por un argumento i moralidad que a la obra he puesto: la qual por ir tan llena de lecion i doctrina, tuvo también necessidad de glossa: i assí la hize lo mas breve que pude, para declarar, i no dar fastidio (Cervantes de Salazar, 1772).

Venegas contribuye a la crítica de la obra brevemente en el prólogo «al benigno i pio lector» planteando una descripción de la moralidad del texto:

En este apólogo se trata de los bienes que están encerrados en el trabajo, i de los grandes i dañosos males que se encubren debajo de la ociosidad. Este apólogo, aunque no es compuesto por el autor, no tiene pequeña parte en él Francisco Cervantes de Salazar, porque además de averle glossado i declarado, le moralizó, que es lo principal que en el se pretende, lo qual no hizo su autor, aunque en la composición dél se mostró hombre docto i prudente (Venegas en Cervantes de Salazar, 1772).

Cerdá y Rico no aporta más noticias sobre el protonotario Luis Mexía, en su «Advertencia», tan solo describe brevemente su argumento recurriendo a las palabras de Cervantes y Venegas. Joaquín García Icazbalceta, en la semblanza biográfica de Cervantes se refiere al Apólogo de la ociosidad i el trabajo, como una «Cansada alegoría» (García Icazbalceta, 1981 p. 52), afirmación que explica la casi inexistente recepción crítica de la obra en el siglo XX.

El único trabajo contemporáneo dedicado al Apólogo lo escribe Briesemeister en 1986. En el artículo, el crítico inserta la obra de Mexia en un contexto, el castellano, en el que aparecen otros textos de la misma temática de autores como Juan de Robles o Domingo de Soto, poniendo en relación las palabras del protonotario con los debates de la época acerca de la miseria y la dignidad del hombre y la reflexión sobre la pobreza y el trabajo.

De las tres obras del volumen, la Introductio ad Sapientiam de Vives es la obra con más difusión. Cervantes se había dedicado a la traducción durante 1541 y 1542, tras su regreso a Flandes, donde conoció a Vives, y la pasó por las prensas de Domenico de Robertis en Sevilla en el año de 1544. La Introductio es uno de los 
textos más estimados del humanista valenciano, como muestran las innumerables ediciones que se han sucedido desde su publicación a principios del siglo XVI:

Después de la primera edición de T. Martens en Lovaina (1524), las reediciones comenzaron inmediatamente. Se reimprimió en Brujas $(H$. de Croock, 1526), París (S. de Colines, 1527), Amberes (M. de Keysere, 1530), otra vez en Lovaina, dos en Basilea y una en Leipzig, durante la vida de Vives. Después, si seguimos el estudio de Tobriner, aparecieron treinta y cinco ediciones posteriores en latín hasta 1732, cuatro ediciones en francés entre 1548 y 1553, una en alemán en 1545, quince en español entre 1544 -en que ve la luz la edición de Burgos, siguiendo los textos latinos corregidos por el propio Vives respecto a la primera edición de 1524- y 1886, otra en español editada en México en 1560, siete en inglés sólo entre 1540 y 1570, hasta, al menos, según sus datos, setenta y seis entre ediciones y reimpresiones. En todo caso, se trató de una difusión extraordinaria (Gómez-Hortigüela, 2001 p. 207).

No obstante, el trabajo de Cervantes ha pasado desapercibido en la recepción de la tradición vivista, pues no se ha vuelto a editar desde 1772. En la edición de Cerdà i Rico, el ilustrado defiende una manera de traducir diferente a la que utiliza el humanista toledano, que no había puesto en romance la Introductio palabra por palabra. El texto ha interesado a investigadores de la recepción vivista en el siglo $X X$, que insisten en la consideración de la obra como un ejercicio retórico de un joven humanista (Moreno, 2006).

\subsection{La aventura americana: actualización bibliográfica y recepción de la Crónica de la Nueva España}

El manuscrito de la Crónica fue hallado a principios de siglo en la Biblioteca Nacional de Madrid por Francisco del Paso y Troncoso. El manuscrito, requisado en 1566, viajó a Madrid y lo utilizaron López de Velasco y Antonio de Herrera en sus trabajos historiográficos. Fue comprada por el Consejo de Indias y pasó por la biblioteca del Conde Duque de Olivares y por la Real Biblioteca. En 1914 Zelia Nuttal encuentra un manuscrito que ya había transcrito el historiador mexicano, aunque sin haber dado noticia de ello. El hallazgo fue celebrado en Londres en el congreso de Americanistas y la polémica se resolvió con dos ediciones de la obra. Francisco del Paso y Troncoso imprimió en Madrid en 1914, en su serie «Papeles de la Nueva España» el tomo primero de la Crónica de Cervantes (Cervantes de Salazar, 1914a). La edición que iniciara el historiador mexicano se finalizó en 1936 en la Ciudad de México, sufragada por el Museo Nacional de Arqueología, Historia y Etnografía (Cervantes de Salazar, 1936). La primera edición completa la llevó a cabo Zelia Nutall en Madrid, patrocinada por The Hispanic Society of America y prólogo introductorio de Manuel Magallón. (Cervantes de Salazar, 1914b).

Agustín Millares Carlo insertó su estudio sobre Cervantes de Salazar al frente de una edición de la Crónica de Nueva España publicada por la editorial Atlas en 1971 en la serie de la Biblioteca de Autores Españoles (Cervantes de Salazar, 1971), y Juan Millares Ostos prologó la primera edición completa mexicana publicada en 1985 por la editorial Porrúa (Cervantes de Salazar, 1985). Existe una edición más 
moderna, del año 2008, publicada en dos volúmenes por la editorial Linkgua Ediciones (Cervantes de Salazar, 2008) y otra patrocinada por la Biblioteca Virtual Miguel de Cervantes, de la Universidad de Alicante, que se basa en el texto editado por Manuel Magallón en 1971 (Cervantes de Salazar, s.f.).

El hallazgo de la Crónica supuso una importante contribución al ciclo cortesiano, pues la historia de Cervantes triplica la narración de Gómara y casi dobla la de Bernal. No obstante, el primer gran trabajo sobre el texto, además de las introducciones de las ediciones de 1914, marcó notablemente el juicio y la estima negativa de la obra. El estudio de Hugo Díaz Thomé insiste en la comparación y en la deuda de Cervantes con Gómara, extrayendo fragmentos prácticamente idénticos de ambas crónicas para justificar el plagio de una narración que siguió en todo a la del cronista de Cortés (Díaz Thomé, 1945).

El juicio ha sido matizado en los trabajos recientes de José Luis Martínez (1994) y Juan Millares Ostos (en Cervantes de Salazar, 1985), en los que se destaca la originalidad de una crónica que fue utilizada entre otros por Antonio de Herrera en al menos ochenta capítulos de su historia indiana. A partir de la consideración objetiva de la Crónica de Cervantes como un texto destacado del ciclo cortesiano, fue además la historia patrocinada por el Cabildo de la Ciudad de México, han aparecido algunos estudios, escasos todavía, que tratan de analizar los temas y la configuración historiográfica y literaria que plantea el humanista toledano en su obra (Plancarte, 1963, Madrigal, 2009).

\subsection{Actualización bibliográfica y recepción del Túmulo Imperial de la gran ciudad de México, México, Antonio de Espinosa, 1560}

El Túmulo Imperial de la gran ciudad de México es una de las obras fundacionales del arte novohispano, pues durante las exequias de la Ciudad de México a Carlos V colaboraron pintores, arquitectos, poetas y humanistas en la configuración de una celebración efímera en la que se construyó un gran monumento funerario adornado con un gran programa iconográfico y literario que honraba la memoria y los hechos del monarca fallecido.

La obra, impresa en casa de Antonio de Espinosa por Cervantes en 1560 con la bendición del virrey Luis de Velasco, fue recuperada por Joaquín García Icazbalceta en el siglo XIX, quien la transcribe completa en la Bibliografía mexicana del siglo $X V I$. Al ejemplar en $4^{\circ}$, con letra romana, le faltan los folios 4 y 5 , y el grabado de la segunda planta el Túmulo, lo que llevó a Manuel Toussaint a delinear una posible reconstrucción gráfica del monumento.

Adelaida Allo Manero parte de un ejemplar diferente en su trabajo doctoral Exequias de la casa de Austria en España, Italia e Hispanoamerica, contenía el grabado completo de los dos cuerpos del túmulo. El ejemplar se conserva en el fondo histórico de la biblioteca de la Universidad Complutense de Madrid $^{3}$ con una encuadernación moderna en piel con hojas de guarda de papel de agua. Según el

\footnotetext{
${ }^{3}$ Signatura BH FLL 29563. El ejemplar es accesible a través de la red en la biblioteca digital Dioscórides de la propia UCM:

[http://alfama.sim.ucm.es/dioscorides/consulta libro.asp?ref=B22329791\&idioma=0]
} 
registro del catálogo aparecen dos exlibris manuscritos, uno de la Casa Profesa de la Compañía de Jesús de Madrid y otro «Es de don Alonso Mexia de Tovar», obispo de Astorga y Mondoñedo a principios del siglo XVII.

Se ha reeditado en dos ocasiones esta obra fundacional de la historia del arte novohispana durante el siglo XX. Una primera sumamente rara, de cien ejemplares numerados, que reproduce en facsímil la edición príncipe conservada en la Henry $\mathrm{E}$. Huntington Library de California, con un breve prólogo publicado en 1939 en México en la editorial Alcancía por Edmundo O'Gorman, Justino Fernández y Federico Gómez como homenaje al IV Centenario del establecimiento de la imprenta en América. La reedición más moderna es la que edita Edmundo O'Gorman en la editorial Porrúa en 1963 con el título de México en 1554 y Túmulo Imperial, que ha venido reimprimiéndose hasta la actualidad.

La descripción de Cervantes es la primera de una fecunda tradición de literatura funeraria oficial durante los siglos del virreinato. El texto narra en varios planos las diferentes manifestaciones artísticas de la ceremonia llevada a cabo en noviembre de 1559. La recepción crítica se focaliza en este sentido en el ámbito de estudio desde el que parten los diferentes acercamientos.

Así, el texto de Cervantes de Salazar ha interesado a la historia de la arquitectura novohispana en trabajos clásicos como los de Pablo de Gante, La arquitectura de México en el siglo XVI, México Porrúa, 1954, George Kubler, Arquitectura mexicana del siglo XVI, México, FCE, 1982, Mario Sartor, Arquitectura y urbanismo en Nueva España. Siglo XVI, México, Azabache, 1992. Desde la misma disciplina, el Túmulo ha sido una obra fundamental en los acercamientos críticos a la figura de Claudio de Arciniega, arquitecto del monumento, en estudios como los de Manuel Toussaint, Claudio de Arciniega, arquitecto de la Nueva España, IIE-UNAM, México, 1981 o los más recientes de Luis Javier Cuesta Hernández, "Sobre el estilo arquitectónico en Claudio de Arciniega», Anales del Instituto de Investigaciones Estéticas, núm, 76, 2000, pp. 61-88 y Arquitectura del Renacimiento en la Nueva España: Claudio de Arciniega, Maestro Maior de la Obra de la Yglesia Catedral de esta ciudad de México, México, Universidad Iberoamericana, 2009.

Desde la historia del arte aparecen numerosos trabajos que vinculan la arquitectura y la pintura del monumento con el humanismo renacentista y su plasmación en la Nueva España. Destacan los estudios comparativos de Francisco de la Maza, Las piras funerarias en el arte y la historia de México, México, 1946, pp. 29-35, de Antonio Bonet Correa «Túmulos del emperador Carlos V», en Archivo Español de Arte, núm. 33, Madrid, 1960, pp. 55-70 y la tesis de licenciatura de J. Abella, Los túmulos de Carlos V en el mundo hispánico, Valladolid y México, Barcelona, 1975.

Encontramos referencias generales y definiciones completas del túmulo en los artículos de Adelaida Allo Moreno en «Exequias del emperador Carlos V en la monarquía hispana» en Carlos $V$ y las artes, Junta Castilla y León/UVA, Salamanca, 2000, en la ficha de Víctor Mínguez, «El túmulo de Carlos V en la ciudad de México «, Ficha 49 del catálogo de la exposición, Los siglos de Oro en los virreinatos de América, 1550-1700, Madrid, 2000, y en los libros de José Miguel Morales Folguera, Cultura simbólica y arte efímero en Nueva España, Junta Andalucía, 
Granada, 1991, pp. 191-198 y en el de Hugo Hernán, Fiesta espectáculo y teatralidad en el México de los conquistadores, México, Iberoamericana, 2009, donde aparece el estudio más completo de la obra hasta ahora, que trata de integrar en el análisis las diferentes partes del relato de Cervantes.

Una de las cuestiones principales de la narración de 1560 es la descripción de las pinturas que aderezaron el catafalco y que conformaron un espectacular programa iconográfico sobre Carlos V. Las referencias principales a la pintura del túmulo aparecen en los estudios clásicos de Manuel Toussaint, Pintura colonial en México, México, UNAM, (IIE), 1965, (1934) y Arte colonial en México, México, UNAM (IIE), 1983 (1948), de Agustín Velázquez Chávez, Tres siglos de pintura colonial mexicana, México, Editorial Polis, 1939, de Abelardo Carrillo y Gariel, Técnica de la pintura en Nueva España, Mexico, UNAM (IIE), 1946, de Diego Angulo Íñiguez y Marco Dorta, Historia del arte hispanoamericano, Salvat, Barcelona, 1950-56 y de José Guadalupe Victoria, Pintura y sociedad en nueva España, siglo XVI, UNAM(IIE), 1986.

Las referencias principales para el estudio del programa simbólico han sido hasta ahora las investigaciones de Francisco de la Maza en Mitología clásica y arte colonial de México, México, UNAM, 1968 y sobre todo en los diferentes trabajos de Santiago Sebastián, entre los que destaca, entre otros, «El programa simbólico del túmulo de Carlos V en Méjico» en Del arte. Homenaje a Justino Fernández, México, UNAM, IIE, 1977, donde el historiador describe los emblemas del catafalco y traza una breve clasificación de los mismos atendiendo a su temática.

Son también decisivos los trabajos de Víctor Mínguez desde la historia del arte, que ha investigado en los últimos años sobre todo la vinculación de este tipo de ceremonias con la implantación del poder en los virreinatos y la situación del indígena ante el nuevo orden imperante y su participación en los festejos en estudios como la «Ficha Túmulo Imperial Carlos V» en VV.AA., Los siglos de oro en los Virreinatos de América, 1550-1700, Madrid, Catálogo Exposición, Sociedad Estatal Conmemoraciones Centenarios Felipe II y Carlos V, 1999. «Espectáculos imperiales en tierras de indios", en VV.AA., La fiesta en la época de Carlos V, SECC, Sevilla, 2000 , p.235 y ss. «La emblemática novohispana», en Las dimensiones del arte emblemático, México, El Colegio Michoacan, 2002. «Efímero mestizo», en Iberoamérica mestiza. Encuentro de pueblos y culturas.Seacex -Fundación Santillana, 2003.

Por último, la descripción de Cervantes ha interesado también sobre todo por ser la primera obra impresa que contiene textos poéticos de corte petrarquista en la Nueva España. Mucho se ha escrito sobre la posible autoría de los mismos desde los comentarios de García Icazbalceta y Menéndez Pelayo (2008), aunque no han aparecido documentos que demuestren las diferentes hipótesis planteadas, que apuntan la mayoría hacia la autoría de diferentes plumas. El debate sobre la autoría y el análisis o la reproducción de los textos castellanos los encontramos en trabajos clásicos como los de Alfonso Méndez Plancarte Poetas novohispanos, primer siglo (1521-1561), México, UNAM, 1942, Jose Pascual Buxó, Muerte y desengaño en la poesía novohispana, México, UNAM, 1972 o Humberto Maldonado, «poesía de fiestas y solemnidades» en Beatriz Garza y George Baudot, Historia de la literatura 
mexicana, México, Siglo XXI, 1996, pp. 461-492. Sobre los textos latinos es indispensable la fecunda labor de José Quiñones Melgoza en diferentes estudios como «Poesía neolatina mexicana del siglo XVI: El túmulo imperial de la gran Ciudad de México», en Memoria del IV encuentro nacional de investigadores de filosofía novohispana, Aguascalientes, UAA-IIF, pp. 232-240; «Cuestiones sociales en el Túmulo Imperial de la gran Ciudad de México (1560), en Saber Novohispano, 2, 1995; «La conciencia de la nacionalidad en el Túmulo Imperial de la gran Ciudad de México", en Saber Novohispano, 2, 1995 y en las referencias de Ignacio Osorio Romero en su recopilación de estudios clásicos Conquistar el eco la paradoja de la conciencia criolla, México, UNAM, 1989.

\section{RESULTADOS}

Como podrá comprobar el lector, la recepción crítica del humanista toledano Francisco Cervantes de Salazar comenzó ya a lo largo del periodo virreinal con el comentario y la edición de algunos ilustres historiadores españoles. Sus manuscritos circularon casi de manera anónima en la entre las manos de cronistas y bibliófilos hasta que de manera decisiva el polígrafo mexicano Joaquín García Icazbalceta rescató y editó sus obras a finales del siglo XIX en el contexto de la Independencia mexicana.

Precisamente fue esta necesidad de construir un imaginario propio la que ha provocado la revalorización académica del humanista toledano, redactor de algunas de las más bellas páginas de la literatura novohispana del XVI, como fueron esos diálogos latinos en los que varios amigos pasean y describen la nueva ciudad de México de los conquistadores, convirtiéndose en la primera alabanza de la ciudad virreinal, que hoy se estudia como uno de los textos fundacionales del México postcortesiano.

Aunque las Obras de 1546 han pasado bastante desadvertidas por la crítica por nadar en un territorio poco definido, tanto su caracterización literaria como la importancia de las obras americanas han difuminado su valor, tanto la Crónica de la Nueva España como el Túmulo Imperial de la ciudad de México se han convertido en obras fundamentales en sus respectivas tradiciones gracias a la recuperación y la interpretación que el siglo XX ha traído consigo.

El hallazgo del manuscrito de la Crónica de la Nueva España en el siglo XX ha reabierto el debate historiográfico en torno al ciclo cortesiano, pues la crónica de Cervantes aporta nuevos datos y una visión diferente de alguno de los episodios decisivos de la Conquista de México. Además, la historiografía humanista de la que bebe Cervantes permite incidir en una de las grandes vías de la tradición literaria hispanoamericana, también en el texto de la Crónica del toledano, la de ficcionalización de la historia como germen del imaginario estético y temático de la literatura hispanoamericana posterior.

\section{REFERENCIAS}

Abella, J. J. (1975). Los túmulos de Carlos $V$ en el mundo hispánico, Valladolid y México [tesis de licenciatura]. Barcelona: [s.e.]. 
Allo Moreno, A. (2000). Exequias del emperador Carlos $\mathrm{V}$ en la monarquía hispana (Ed.), en Carlos V y las artes. Salamanca, España: Junta Castilla y León/UVA.

Angulo Íñiguez D. y Marco Dorta, E. (1950-1956). Historia del arte hispanoamericano. Barcelona: Salvat.

Antonio, N. (1996). Bibliotheca Hispana Nova, ed. facsímil de la ed. de Madrid, Imprenta de Ibarra, 1783, pp. 414-415. Madrid: Visor Libros.

Baranda, C. (2003). De Pérez de Oliva a Cervantes de Salazar: homenaje y traición. Ínsula, 674, 22-24.

Bonet Correa, A. (1960). Los Túmulos del emperador Carlos V, en Archivo Español de Arte, 33, 55-65.

Briesemeister, D. (1986). L'Apologie du travail dans l'Espagne du XVI siècle. Luis Mexia et son Apologo de la ociosidad y el trabajo (1546), en Melànges offerts à Alain Guy, Philosophie XII, XIII, XIV, t. 1, 101-120.

Capmany, A. (1848). Teatro histórico-crítico de la elocuencia española. Barcelona: Imprenta de Joan Gaspar, 150-160.

Carrillo y Gariel, A. (1946). Técnica de la pintura en Nueva España. México: UNAM (IIE).

Cerdá i Rico, F. (1772). Advertencias sobre esta nueva impresión, en Francisco Cervantes de Salazar, Obras que Cervantes de Salazar ha hecho, glosado y traducido, pp. I-XIV. Madrid: Imprenta de Antonio de Sancha.

Cerrón Puga, M. L. (1995). “Introducción”, en Hernán Pérez de Oliva, Diálogo de la dignidad del hombre. Razonamientos. Ejercicios. Madrid: Cátedra (Letras Hispánicas).

Cervantes de Salazar, F. (1544). Introducción para ser sabio compuesta en latín: por el doctísimo varón Luis Vives vuelta en castellano por Francisco Cervantes de Salazar. Sevilla: Domenico de Robertis.

Cervantes de Salazar, F. (1546). Obras que Francisco Cervantes de Salazar, ha hecho, glosado y traducido. La primera es la Introducción y camino para la sabiduría, donde se declara que cosa sea, y se ponen grandes avisos para la vida humana, compuesta en latín por el excelente varón, Luis Vives, vuelta en castellano, con muchas adiciones que al propósito hacían por Francisco Cervantes de Salazar. La segunda es Apólogo de la ociosidad y el trabajo, intitulado Labricio Portundo, donde se trata con maravilloso estilo de los grandes males de la ociosidad, y por el contrario de los provechos y bienes del trabajo, compuesto por el Protonotario Luis Mexía, glosado y moralizado por Francisco Cervantes de Salazar. La tercera es un Dialogo de la dignidad del hombre, donde por manera de disputa se trata de las grandezas y maravillas que hay en el hombre y por el contrario de sus trabajos y miserias, comenzado 
por el maestro Oliva y acabado por Francisco Cervantes de Salazar. Alcalá de Henares: Juan de Brocar.

Cervantes de Salazar, F. (1560). Túmulo Imperial de la gran ciudad de México. México: Antonio de Espinosa.

Cervantes de Salazar, F. (1772). Obras que Francisco Cervantes de Salazar ha hecho, glosado y traducido. Diálogo de la dignidad del hombre por el M. Oliva y por Cervantes. Apólogo de la ociosidad y el trabajo, intitulado Labricio Portundo, por Luis Mexía, glosado por F. Cervantes. Introducción y camino para la sabiduría compuesta en latín, como va ahora, por Juan Luis Vives, vuelta en castellano con muchas adiciones por el mismo Cervantes, ed. de Francisco Cerdá i Rico. Madrid: Antonio de Sancha.

Cervantes de Salazar, F. (1914a). Crónica de Nueva España escrita por el Doctor y Maestro Francisco Cervantes de Salazar, Cronista de la Ciudad de México, tomo I. (Papeles de Nueva España compilados por D. Francisco del Paso y Troncoso. Tercera Serie: Historia). Madrid: Hauser y Menet.

Cervantes de Salazar, F. (1914b). Crónica de la Nueva España, ed. Zelia Nutall, prol. de Manuel Magallón. Madrid: Hispanic Society of America.

Cervantes de Salazar, F. (1936). Crónica de Nueva España escrita por el Doctor y Maestro Cervantes de Salazar, Cronista de la Ciudad de México, tomos II y III. México: Talleres Gráficos del Museo Nacional de Arqueología, Historia y Etnografía, (Papeles de Nueva España compilados por D. Francisco del Paso y Troncoso, Tercera Serie: Historia).

Cervantes de Salazar, F. (1939), Túmulo Imperial de la gran ciudad de México impreso en la gran Ciudad de México por Antonio de Espinosa en 1560, ed. facsimilar del ejemplar de la Henry E. Huntington Library and Art Gallery, ed. de Justino Fernández y Edmundo O’Gorman, prol. de Federico Gómez de Orozco, México: Alcancía.

Cervantes de Salazar, F. (1971). Crónica de la Nueva España, ed. de Manuel Magallón, introducción de Agustín Millares Carlo. Madrid: Atlas.

Cervantes de Salazar, F. (1985). Crónica de la Nueva España, ed. y prol. de Juan Miralles Ostos. México: Porrúa.

Cervantes de Salazar, F. (1985). México en 1554 y Túmulo Imperial, $1^{\text {a }}$ ed. 1963, edición, prólogo y notas de Edmundo O’Gorman. México: Porrúa.

Cervantes de Salazar, F. (2008), Crónica de la Nueva España. Linkgua Digital.

Cervantes de Salazar, F. [s.f.], Crónica de la Nueva España, ed. digital a partir de Francisco Cervantes de Salazar (1971) Crónica de la Nueva España ed. de Manuel Magallón, Madrid: Atlas. Alicante: Biblioteca Virtual Miguel de 
Cervantes. Recuperado de http://www.cervantesvirtual.com/obra/cronica-de-lanueva-espana--0/

Cuesta Hernández, L.J. (2000). Sobre el estilo arquitectónico en Claudio de Arciniega, en Anales del Instituto de Investigaciones Estéticas, 76, 61-88.

Cuesta Hernández, L.J. (2008). México insigne honras celebro a su rey: algunas precisiones sobre el ceremonial fúnebre de la dinastía de los Austrias en la Nueva España, en Vía Spiritus, 15, 111-136.

Cuesta Hernández, L.J. (2009). Arquitectura del Renacimiento en la Nueva España: Claudio de Arciniega, Maestro Maior de la Obra de la Yglesia Catedral de esta ciudad de México. México: Universidad Iberoamericana.

De Gante, P. (1982). La arquitectura de México en el siglo XVI, México: Porrúa.

De la Maza, F. (1946), Las piras funerarias en la historia y el arte de México. México: UNAM.

De la Maza, F. (1968), La mitología en el arte colonial de México. México: UNAM.

Díaz Thomé, J.H. (1945). Francisco Cervantes de Salazar y su Crónica de la conquista de la Nueva España en Ramón Iglesia (ed.), Estudios de historiografía de la Nueva España, pp. 15-47. México: El Colegio de México.

García Icazbalceta, J. (1981). Bibliografía mexicana del siglo XVI: catálogo razonado de libros impresos en México de 1539 a 1600: con biografías de autores y otras ilustraciones: precedido de una noticia acerca de la introducción de la imprenta en México. México: FCE.

Gómez-Hortigüela, Ángel (2001). La sabiduría como virtud en Juan Luis Vives, en Juan Luis Vives, Introducción a la sabiduría, pp. 99-298. Valencia: Ajuntament de València.

Guadalupe Victoria, J. (1986). Pintura y sociedad en nueva España, siglo XVI. México: UNAM (IIE).

Hernán Ramírez, H. (2009). Fiesta espectáculo y teatralidad en el México de los conquistadores. México: Iberoamericana.

Kubler, G. (1983). Arquitectura mexicana del siglo XVI. México: FCE.

Madrigal, J.L. (2003). Cervantes de Salazar, autor del Lazarillo, en Artifara, (2). Recuperado de http://www.cisi.unito.it/artifara/rivista2/testi/cervlazar.asp

Madrigal, J.L. (2009). "Francisco Cervantes de Salazar y su Crónica de la Nueva España», en Guillermo Serés (Coord.), Los límites del océano: estudios filológicos de crónica y épica en el nuevo mundo, pp. 75-89. Barcelona: Bellaterra. 
Maldonado, H. (1996). Poesía de fiestas y solemnidades, en Beatriz Garza y George Baudot Historia de la literatura mexicana, pp. 461-492. México: Siglo XXI.

Martínez Baracs, R. (2007). Triunfo de la virgen y gozo mexicano, en Revista Literatura Mexicana, XVIII(2).

Martínez, J. L. (1993). Rescate de Francisco Cervantes de Salazar. Discurso de ingreso en la Academia Mexicana de la Historia, 2 de marzo de 1993, en Memorias de la Academia Mexicana de la Historia, (vol. XXXVI), pp. 191-239. Recuperado de http://acadmexhistoria.org.mx/PDF/SILLON 28 JOSE L MARTINEZ.pdf

Martínez, J. L. (1994). La Crónica de la Nueva España, de Francisco Cervantes de Salazar, en Julio Ortega, José Amor y Vázquez y Rafael Olea Franco (coords.), Conquista y contraconquista, la escritura del Nuevo Mundo: actas del XXVIII Congreso del Instituto Internacional de Literatura Iberoamericana, pp. 149-158. México: El Colegio de México.

Méndez Plancarte, A. (1942-1945), Poetas novohispanos. México: UNAM.

Menéndez Pelayo, M. (2008). Historia de la poesía hispanoamericana, Edición digital de la Biblioteca Virtual Miguel de Cervantes, t. 1, p. 21. Recuperado de http://www.cervantesvirtual.com/obra/historia-de-la-poesia-hispanoamericana-t$1--0 /$

Millares Carlo, A. (1986). Apuntes para un estudio biobliográfico del humanista Francisco Cervantes de Salazar, en Agustín Millares Carlo, Cuatro estudios biobibliográficos mexicanos. México: FCE.

Mínguez, V. (1999). El Túmulo Imperial Carlos V en la ciudad de México, [ficha 49 catálogo de la exposición], en Los siglos de oro en los Virreinatos de América, 1550-1700. Madrid: Sociedad Estatal Conmemoraciones Centenarios Felipe II y Carlos V.

Mínguez, V. (2000). Espectáculos imperiales en tierras de indios, en La fiesta en la época de Carlos V, pp. 235 y ss. Sevilla: SECC.

Mínguez, V. (2002). La emblemática novohispana, en Las dimensiones del arte emblemático. México: El Colegio de Michoacán.

Mínguez, V. (2003). Efímero mestizo, en Iberoamérica mestiza. Encuentro de pueblos y culturas. Madrid: Seacex- Fundación Santillana.

Miralles Ostos, J. (1985). Introducción, en Francisco Cervantes de Salazar, Crónica de la Nueva España. México: Porrúa.

Mora Plancarte, I. (1963). Cervantes de Salazar, el dramaturgo de la conquista. México: UNAM. 
Morales Folguera, J. M. (1991). Cultura simbólica y arte efímero en Nueva España. Granada: Junta de Andalucía.

Moreno, V. (2006). La recepción hispana de Juan Luis Vives. Valencia: Generalitat Valenciana.

Nutall, Z. (1912). La Crónica o Historia de las Indias por Cervantes de Salazar. En Boletín de la Sociedad Mexicana de Geografía y Estadística, 5ª época, V, 367376.

Nutall, Z. (1921). Francisco Cervantes de Salazar, Biographical Notes, en Journal de la Societé des Américanistes de Paris, 13, 59-90.

Osorio Romero, I. (1989). Conquistar el eco la paradoja de la conciencia criolla, México: UNAM.

Pascual Buxó, J. (1975). Muerte y desengaño en la poesía novohispana: siglos XVI, XVII. México: UNAM.

Paso y Troncoso, F. (1914). "Introducción", en Francisco Cervantes de Salazar, Crónica de Nueva España, tomo I. Madrid: Hauser y Menet.

Quiñones Melgoza, J. (1992). "Poesía neolatina mexicana del siglo XVI: El túmulo imperial de la gran Ciudad de México", en Memoria del IV encuentro nacional de investigadores de filosofía novohispana, Aguascalientes, UAA-IIF, pp. 232240.

Quiñones Melgoza, J. (1995a). "Cuestiones sociales en el Túmulo Imperial de la gran Ciudad de México (1560)”, en Saber Novohispano, 2, 459-469.

Quiñones Melgoza, J. (1995b). "La conciencia de la nacionalidad en el Túmulo Imperial de la gran Ciudad de México", en Saber Novohispano, 2, 471-478.

Rico, F. (2005). El pequeño mundo del hombre, Barcelona: Destino.

Sanchis Amat, V.M. (2015a). La recepción de los diálogos de México en 1554 de Francisco Cervantes de Salazar: apuntes bibliográficos, en Tiempo y Escritura, 28, 39-55. Recuperado de www.azc.uam.mx/publicaciones/tye/articulos/TyE 28/TyE28.pdf

Sartor, M. (1992). Arquitectura y urbanismo en Nueva España. Siglo XVI. México: Azabache.

Sebastián, S. (1977). El programa simbólico del túmulo de Carlos $V$ en Méjico. México: UNAM.

Toussaint M. (1965). Pintura colonial en México. México: UNAM (IIE). 
Toussaint, M. (1981). Claudio de Arciniega, arquitecto de la Nueva España. México: UNAM.

Toussaint, M. (1983). Arte colonial en México. México: UNAM (IIE).

Velázquez Chávez, A. (1939). Tres siglos de pintura colonial mexicana. México: Editorial Polis. 